\title{
DECISION TREES TO SELECT BEST RESPONSE STRATEGIES AFTER OIL SPILL IN AQUATIC ECOSYSTEMS
}

\author{
Handerson A. A. Lanzillotta ${ }^{1}$ \\ Marcia Marques ${ }^{1,2}$ \\ ${ }^{\prime}$ Rio de Janeiro State University-UERJ, Brazil \\ ${ }^{2}$ University of Kalmar-HIK, Sweden \\ ${ }^{3}$ Alpina Briggs Environmental Defence, Brazil
}

\begin{abstract}
The response to spills in aquatic system include decisions that must be taken almost immediately after the accident has been noticed. Choosing the wrong strategy can result in larger and sometimes irreversible environmental impacts, which in turn may result in severe socio-economic consequences, such as suspension of fishing practices in the affected areas, impacts on tourism and recreation, etc. Every hour that passes after the accident count, since the oil spreads and the weathering processes to begin. This process changing physicalchemical properties and limits the effectiveness of containment, chemical dispersant and in situ burning. If the response is slow to start, dependent on the oil properties, it may sink or reach coastal zones making the impacts even greater, including the generation of larger amounts of oily residues to be dealt with. This paper presents strategic responses that can be undertaken under the format of decision trees, having as the starting point the type of the oil that has been spilled. Since the most appropriate options are dependent on various variables, including oceanographic and meteorological conditions, the decision trees are seen as one of many useful tools that can support decision processes after an incident takes place.
\end{abstract}

\section{KEYWORDS}

strategic response, contingency plan, skimmers, dispersants, coastal clean-up, waste management

\section{INTRODUCTION}

Regardless of changes that are expected to occur in the world's energy needs, petroleum products will remain high during the next decades as the main energy source. Where technological progress has been done, accidents with crude oil and oil refining products happen mainly during routine operations of extraction, transport, storage, refining and distribution. The environmental impacts resulting from oil spills can severely affect coastal ecosystems as well as submersed habitats, interrupting fishing and recreation, demanding expensive counter measures. The decision of how, when and to what extension action shall be taken defines the severity of each one of the impacts resulting from an oil spill incident [1]. Incidents with oil have been reported since petroleum started to be commercially explored in the western world during the $19^{\text {th }}$ century. However, it was during the $20^{\text {th }}$ century, particularly during the 1960's that maritime disasters, mostly related to oil transportation in large scale reached high proportions, as a consequence of the international commerce and increase in tanker size [2]. It was during this period that the magnitude and severity of the 
environmental as well as the socio-economic impacts reached unprecedented proportions. Immediately after the occurrence of an incident, lack of information or wrong/incomplete information is the most common situation. Relevant information that defines the dimension of an incident includes: spilled volume, type of oil and its physical-chemical characteristics, environmental conditions at the moment the incident occurred and afterwards (oceanographic and meteorological conditions, including temperature, tide, wind, proximity to the coast, etc). The interactions among these variables can result in a large number of scenarios and a complex set of options for response [4]. Since every incident is unique, in order to select the best site-specific response strategy, the knowledge regarding these variables is essential.

The beginning of an emergency is always characterized by choices and actions that include personnel and equipment mobilization. Incidents occurring close to well-equipped terminals and harbors are often benefited by the availability of infrastructure and equipment for a fast response. However, when the incident occurs along the coastal line the difficulties and the time required for a prompt response are greater. A large-scale spill requires the use of the Net Environmental Benefit Analysis (NEBA) [3]. Sometimes it is necessary to choose what ecosystem among several shall be protected first: a beach, the entrance of a mangrove, etc since during the first hours and days, the resources and personnel available might be limited. When new resources arrive and qualified personnel take their positions according to the Contingence Plan, some of the ecosystems might be already seriously affected. Additionally, some strategies for response can cause environmental impact and such impacts must be weighed against the impacts caused by the incident itself. Depending on the extension of the spill, cleaning a mangrove area with a staff of 20 professionals, for instance, might cause more impacts to the environment than the spilled oil. A fast response has the objective of preventing the oil spreading; the faster the response, the smaller the impacted area will be. After oil containment, the main concern is to reduce as much as possible the extension of the impacted area, which will also result in less costs for cleaning, lower penalties and indemnifications to be paid and less costs for treatment and final disposal of the residues generated. Therefore, the key to a successful response to an oil spill incident is the speed in which it is implemented. It is necessary to promote continuous development and improvement of tools that might help to reduce the time required between the accident and the action, besides the need for continuous improvement of the effectiveness achieved. Based on the lessons learned from large incidents over the years, Contingency Plans as well as administrative processes must be continuously improved. Sensitivity Maps must be constantly updated, as well as software packages, equipments for oil remote detection and management tools, such as decision trees are useful for decision making processes. From one side, decision trees must reflect the technological and scientific progress in the area, on the other they must consider scenarios of limited resources under which, action must be taken.

This paper briefly presents the main aspects to be taken into consideration for a fast and effective response to oil spill incidents with emphasis on the marine environment, and present some decision trees developed for accidents with different types of oils, when specific choices must be done within a very short time.

\section{METHODOLOGY}

In order to develop the decision trees, the bibliographic survey included international and Brazilian regulations relevant to the subject, a review of some large incidents at the sea and the strategic responses applied, as well as scientific literature. The professional experience of the first author in the field as member of the Alpina Briggs Environmental Defense Ltd was useful to the development of the project. Interviews and discussions were carried out with senior professionals with practical experience during the development of the work. The trees 
were constructed to support decisions at different stages of responses to oil spill incidents, including selection of the most appropriate cleaning technique, appropriate categories of booms and skimmers, applicability and efficiency of different coast cleaning procedures under different scenarios, oil types and environmental conditions, disposal strategy for oily waste. Whenever coastal cleaning applies the trees focus mainly on options applicable to geomorphologic profiles found in the Brazilian coast. The following variables were selected as the main components for the decision trees here presented: (i) type of oil; (ii) oil weathering; (iii) oceanographic conditions; (iv) meteorological conditions; (v) access to the affected areas.

\section{RESULTS}

\subsection{Regulatory tools}

The list of important regulatory milestones for the sector includes international conventions and regulations such as: The Protocol of 1978 relating to the 1973 International Convention for the Prevention of Pollution from Ships (MARPOL, 73/78) and the International Convention on Oil Pollution Preparedness, Response and Cooperation in 1990 (OPRC 90) established during the $16^{\text {th }}$ International Maritime Organization (IMO) meeting (London 30/11/90). The latter convention has the purpose of establishing mechanisms of cooperation between organizations and countries to respond to large oil spills at sea. Other mechanisms of control are the IMO demands for ships, such as the International Safety Management (ISM) Code.

\subsection{Emergency plan}

One of the responsibilities of the response team, particularly its leader, is to define the combination of strategies and techniques to be included in the response. The list of techniques have "windows of opportunity" and these "windows" are defined by the amount and type of spilled oil, the environmental conditions at the moment the incident occurred and afterwards, persistence of the product and emulsion formation, environment and ecosystems threaten.

After an incident has been registered, a series of pre-defined emergency responses will be triggered; in other words, all actions included in an emergency plan previously tested and approved by an environmental agency. A series of procedures must be followed in order to obtain an appropriate and fast response. The team leader must know in detail all the work to be done and be familiar with the type of the environment affected.

\subsubsection{Personnel qualification:}

According to national and international regulations, all activities related to response to oil spills at sea shall be carried out by companies that have registration and license to conduct these activities. The company will be responsible and the industry co-responsible for any incident that might occur during the sea and coastal cleanup, storage, transportation, treatment and final disposal of the residues as part of the response to the incident. The response team shall include professionals trained in specific aspects included in the response and shall have previous field experience to operate equipment and implement procedures, including containment and recovery equipment, vessel operation, application of chemical products, coastal cleaning procedures and an efficient communication system. The professional responsible for coordinating the activities must have knowledge of the physical, chemical, geological and biological aspects related to the contingency plan and the potential impacts [11]. Carrying out simulations, different strategies for response should be tested and evaluated under different environmental conditions as part of the training and personnel qualification. 
Unfortunately, it is common that during the first hours after an accident the situation is characterized by insufficient information leading to wrong decisions, regardless the long list of tasks to be undertaken. In this list, fast assessment of risks associated to the spilled product must be included.

\subsection{Basic characteristics of the sea}

The basic condition of the sea at the moment the spill occurs is shown in Table 1.

Table 1. Basic condition of the sea conditions at the moment of the incident.

\begin{tabular}{c|c|c}
\hline Environment & Waves height $(\mathbf{m})$ & Wind speed $(\mathbf{k m} / \mathbf{h})$ \\
\hline Calm waters & Less than 0.3 & Less than 10 \\
\hline Enclosed waters & Between 0.3 and 2.0 & Between 10 and 30 \\
\hline Open sea & 2.0 or more & 30 or more \\
\hline
\end{tabular}

\subsection{Basic characteristics of the oil}

The type of oil is an important variable that will define choices to be taken after the spill. The strategy for response presented here is based on 4 groups of oil: Group I, II, III and IV [7] ( Tab 2). Although inside each oil group a wide variability exists regarding the relative content of different hydrocarbons and inorganic substances, this basic classification supports the decision process. The background for using the oil group as a basic criterion is related to the fact that it was previously observed that different types of oil have different removal rates from the surface (Fig 1) and differ regarding risk of explosion.

Tahle 2. Oils classification based on the International Tanker Owners Pollution Federation (ITOPF, 1987), adapted by [5].

\begin{tabular}{cccccc}
\hline ITOPF & Density & ${ }^{\mathbf{0}}$ API & Classification & Half life & Persistence \\
\hline Group I & $<0,8$ & $>45$ & Very light & $\sim 24 \mathrm{~h}$ & $1-2$ days \\
Group II & 0,8 a 0,85 & 35 a 45 & Light & $\sim 48 \mathrm{~h}$ & $3-4$ days \\
Group III & 0,85 a 0,95 & 17,5 a 35 & Medium & $\sim 72 \mathrm{~h}$ & $6-7$ days \\
Group IV & $>0,95$ & $<17,5$ & Heavy & $\sim 168 \mathrm{~h}$ & $>7$ days \\
\hline
\end{tabular}

\subsection{Technological options}

Two lessons learned during large oil spills in history, when inappropriate response occurred are: (i) in many cases, the cleaning of the spill and the environmental recovery were possible if appropriate actions had been undertaken and proper technology had been chosen; (ii) nature can be responsible for a large part of this recovery process if proper measures to optimize natural attenuation are implemented in time [12]. Several techniques for containment, recovery and cleaning are available nowadays such as: natural attenuation, 
berms, manual and mechanical oil removal, sorbents, vacuuming, debris removal, vegetation cutting, re-working of oiled substrate, flushing with low or high pressure cold/ hot water, steam cleaning, solidifiers, shoreline cleaning agents, nutrient enrichment (promotion of bioremediation), microbial treatment and in-situ burning. Several response strategies require previous authorisation from the environmental agency. In this paper, the focus is given to the strategies described by the state environmental agency CETESB [5], State of Sao Paulo, Brazil.

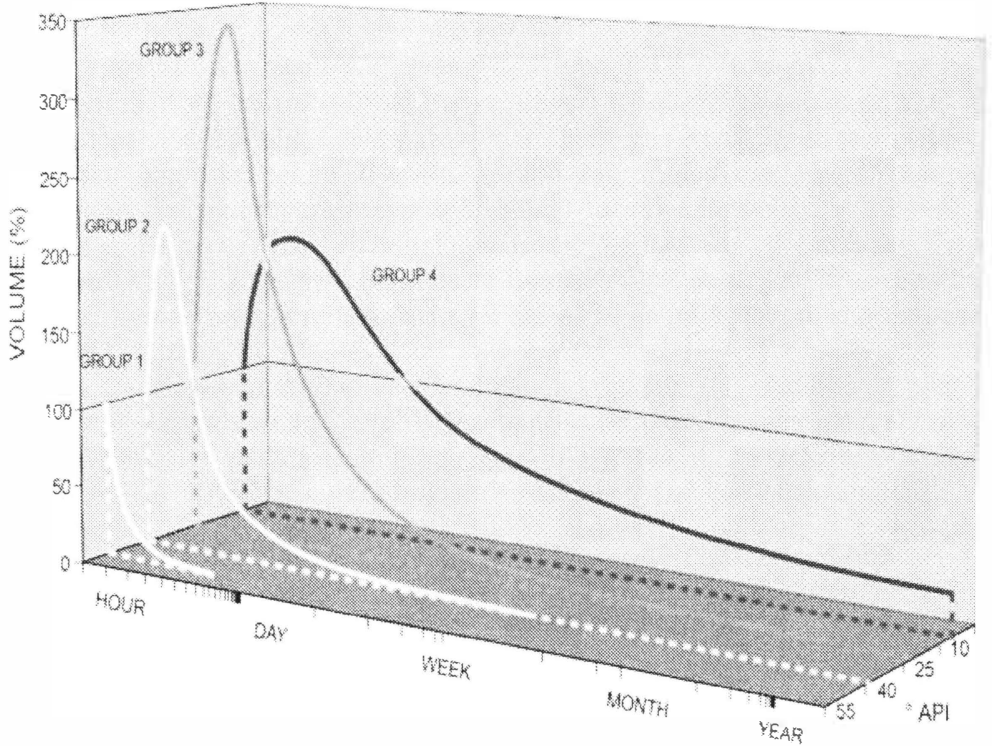

Figure 1. Oil removal (\% volume) from the surface, according to the oil characterization in groups I (very light), II (Light), III (Medium) and IV (Heavy) [6].

\subsection{Basic response strategy according to the type of spilled oil}

Group I: Oils classified in Group I are formed by very light, volatile hydrocarbons, easily degradable which generate the formation of small amounts of instable mousses low-density foam and iridescent films. Usually weathering processes are important factors to promote contaminant reduction and minimize local impacts. The main weathering processes are photo-oxidation, biodegradation, spreading, volatiles and natural dispersion in the water column. In warm climates, such as tropical areas, these processes are intensified compared to temperate climate. The response to incidents involving oils of Group 1 must be carefully implemented, since there containment might form an explosive atmosphere, due to characteristics of high volatiles and low flash point. Therefore containment is not recommended in this case. There are remotely operated pumps activated by hydraulic systems that work immersed in oil. All equipment for this type of work shall be intrinsically safe, but possibilities of collecting this type of spilled oil using boats and other equipment is not safe, due to risks of explosion and the formation or clouds of vapour rich with monoaromatic hydrocarbons. The application of dispersants is not necessary since the water solubility is high. The basic response options proposed for oil of Group I are shown in Fig 2. 
Group II: Oils classified in Group II are mostly formed by hydrocarbons that are light, volatile, with tendency to form stable mousses and large quantity of foam during the first days of weathering. The flash point of the spilled material should be known and the formation of an explosive atmosphere shall be verified by using an oxygen explosimeter. It is very common during incidents with this type of oil that the only thing to be done is to promote deflection of the plume in order to protect the most sensible areas. Containment and recovery is only possible when the local conditions are favorable. Coastline cleaning is recommended in the worse cases. The basic response options proposed for oil of Group II are shown in Fig 3.

Group III: Oils classified in Group III (medium) are mostly formed by hydrocarbons that show the tendency to form dense and stable mousses, which under adverse meteorological and oceanographic conditions behave like oils in Group II; under calm and stable climate conditions, Another option is the use of chemical dispersants, as long as they fulfill the requirements established by the environmental regulation [8]. Oils type III remain in the environment and shows degradability by natural attenuation similar to oils in Group IV. The basic response options proposed for oil of Group III are shown in Fig 4.

Group IV: Oils in this group (IV) are heavy, with tendency to form dense and stable mousses that remain in the environment during more than seven days. The weathering process results in dense pellets and plaques. If the sea offers conditions for that, oil containment and recovery is recommended. The basic response options proposed for oil of Group IV are shown in Fig 4.

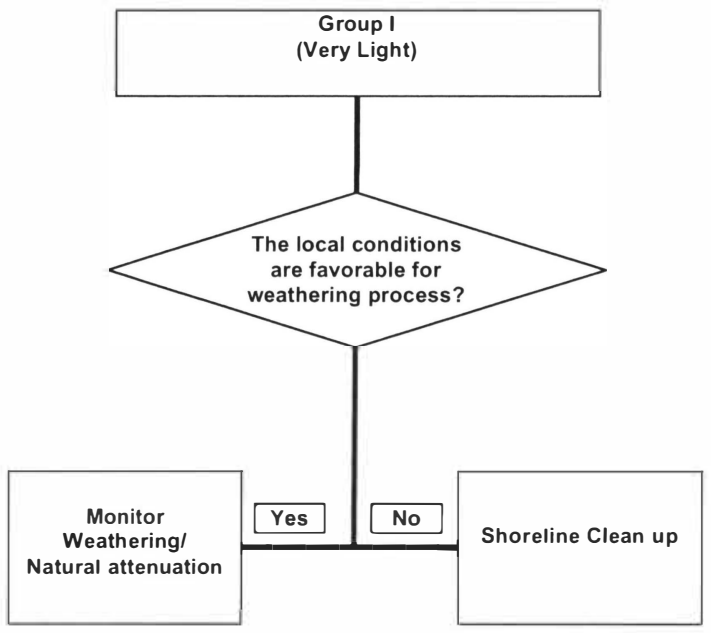

Figure 2. Response strategy for spill of oil Group I (very light). 


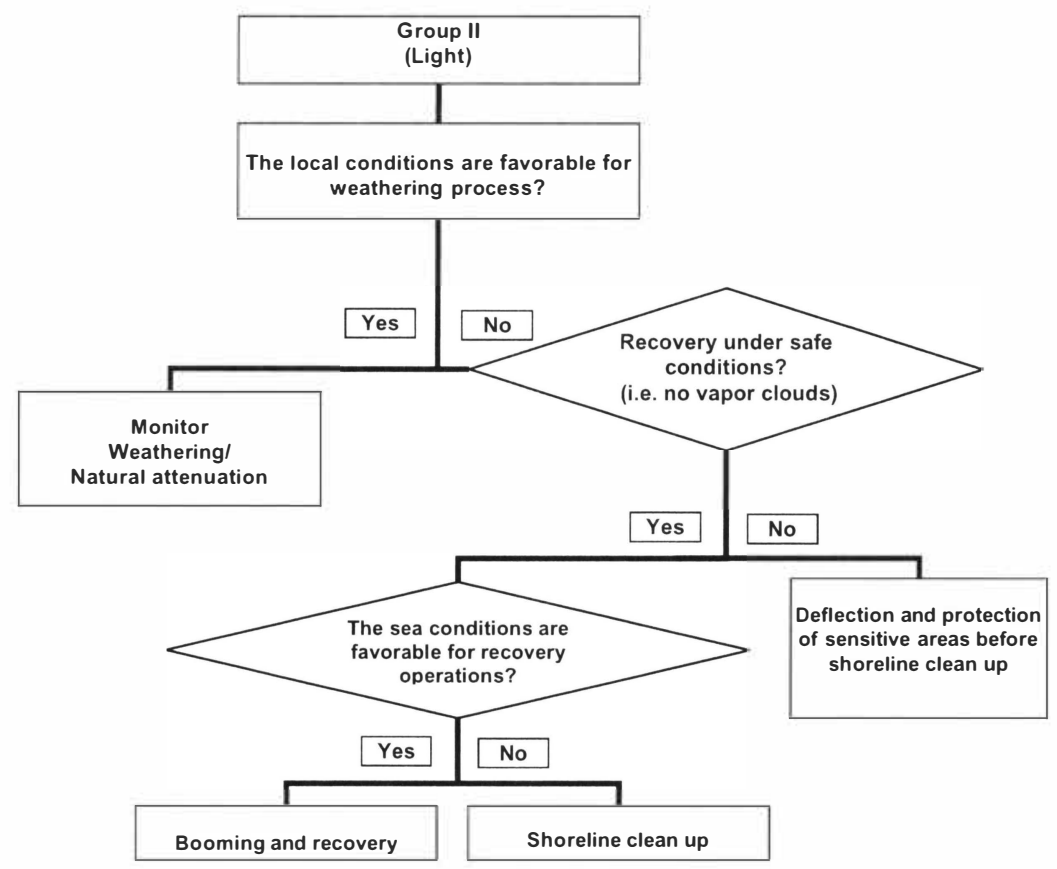

Figure 3. Response strategy for spill with oil Group II (light). 
Kalmar ECO-TECH '07

KALMAR, SWEDEN, November 26-28, 2007

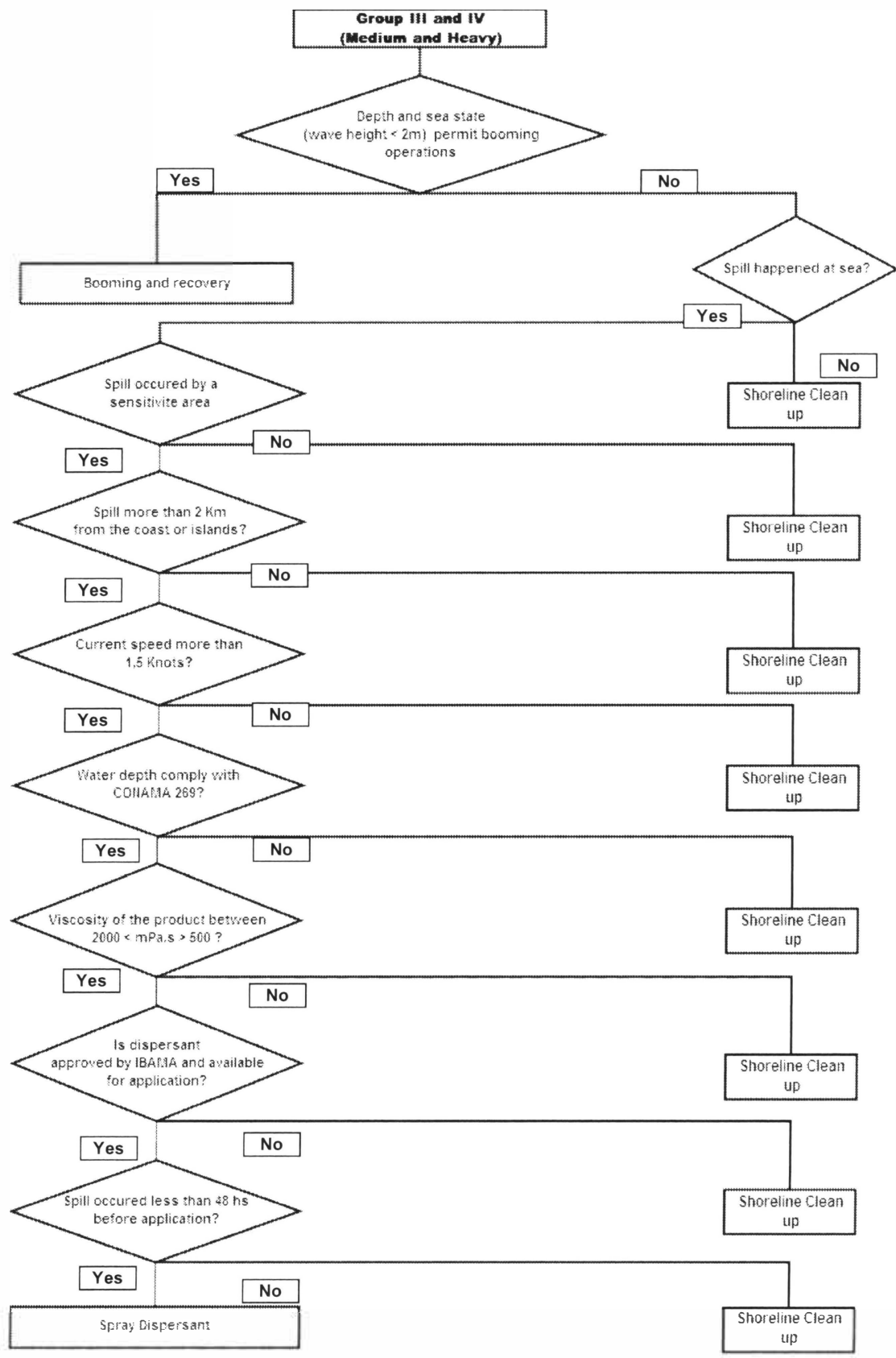

Figure 4. Response strategy for spills with oil Groups III and IV. 


\subsection{Shoreline clean up strategy selected according to costal ecosystem and the type of oil}

Group I: Since the oils are very light and evaporate very quickly, natural attenuation is the most appropriated method in many cases. Due to the high toxicity high mortality rate among shellfish and invertebrates in muddy areas at low tide are expected. Shoreline cleanup options for Group I are shown in Fig 5.

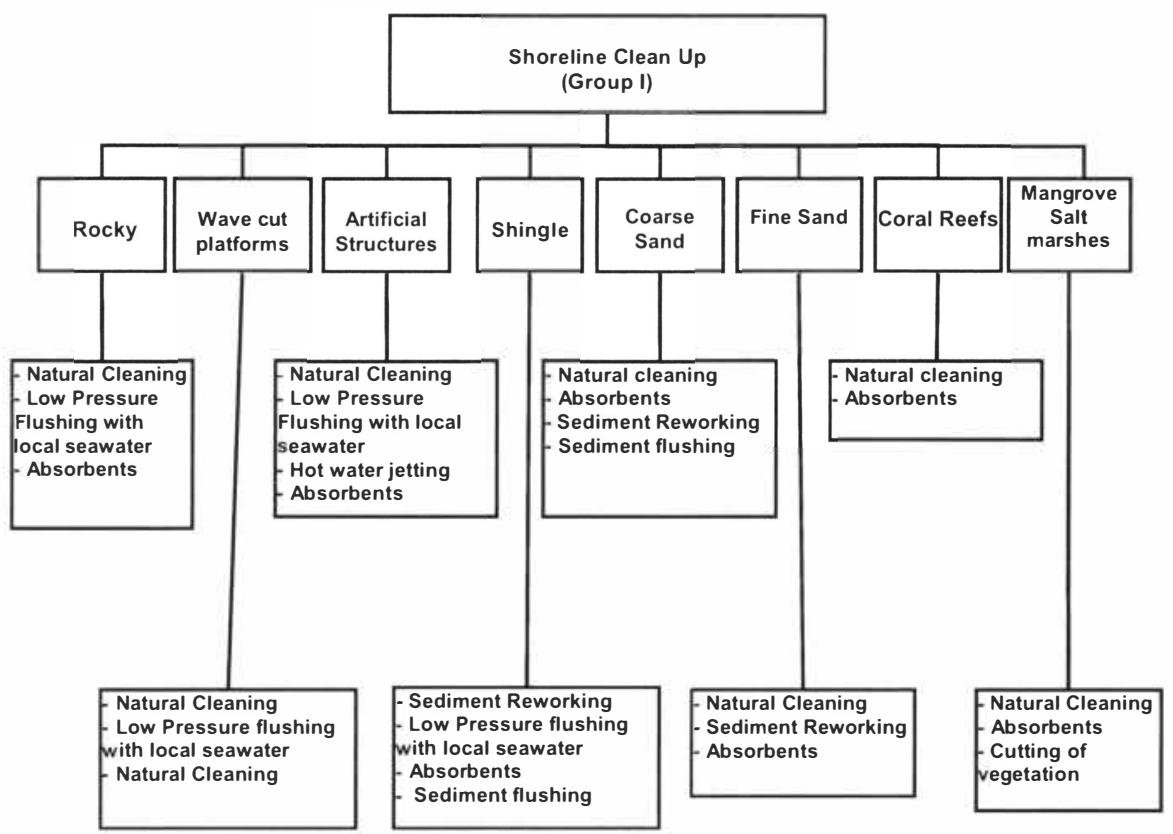

Figure 5. Decision tree for strategy of shoreline clean up - spill with oil Group I.

Group II: Light oils, with natural attenuation slow in low energy shorelines. Therefore, manual cleanup approach is usually the best option to remove the oil more quickly. In tropical regions the evaporation is usually higher, resulting in less manual cleanup methods being used. If allowed to weather, this type of oil will resemble Group III when it comes ashore. Shoreline cleanup options proposed for oil Group II are shown in Fig 6. 


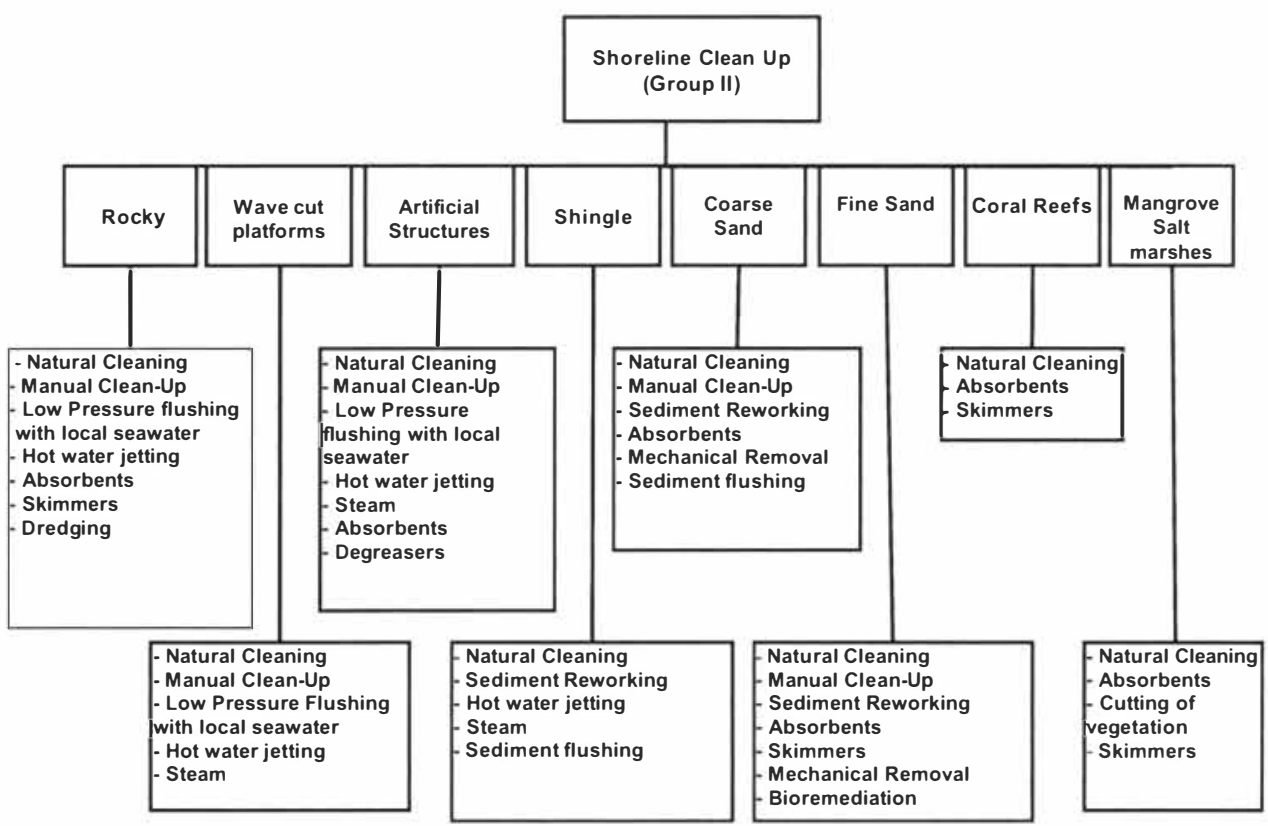

Figure 6. Decision tree for strategy of shoreline clean up - spill with oil Group II.

Group III: Many cleanup techniques mentioned in this text are suitable for this type of oil, due to little evaporation. Depending on the amount of asphaltenes - a complex hydrocarbon with very high molecular weight - oils type III can become emulsified (mousse), thus becoming much more persistent. During early stages of an oil spill or if a continuous leak is occurring, depending on the location or the season, dispersants can be used at sea to reduce the coastal impacts. If allowed to weather the oil will come ashore resembling Group IV oil. Shoreline cleanup options proposed for oil Group III are shown in Fig 7.

Group IV: Heavy oils due to high persistence may remain in the environment for many years if no effective cleanup method is applied. These oils have a smothering effect, coating plants thus, stopping the breathing of photosynthesis processes, depending on the specie. Young mammals may also be smothered, resulting in a blockage of transpiration and heat exchange with the environment, when death occurs. Shore line cleanup options proposed for oil Group IV are shown in Fig 8. 


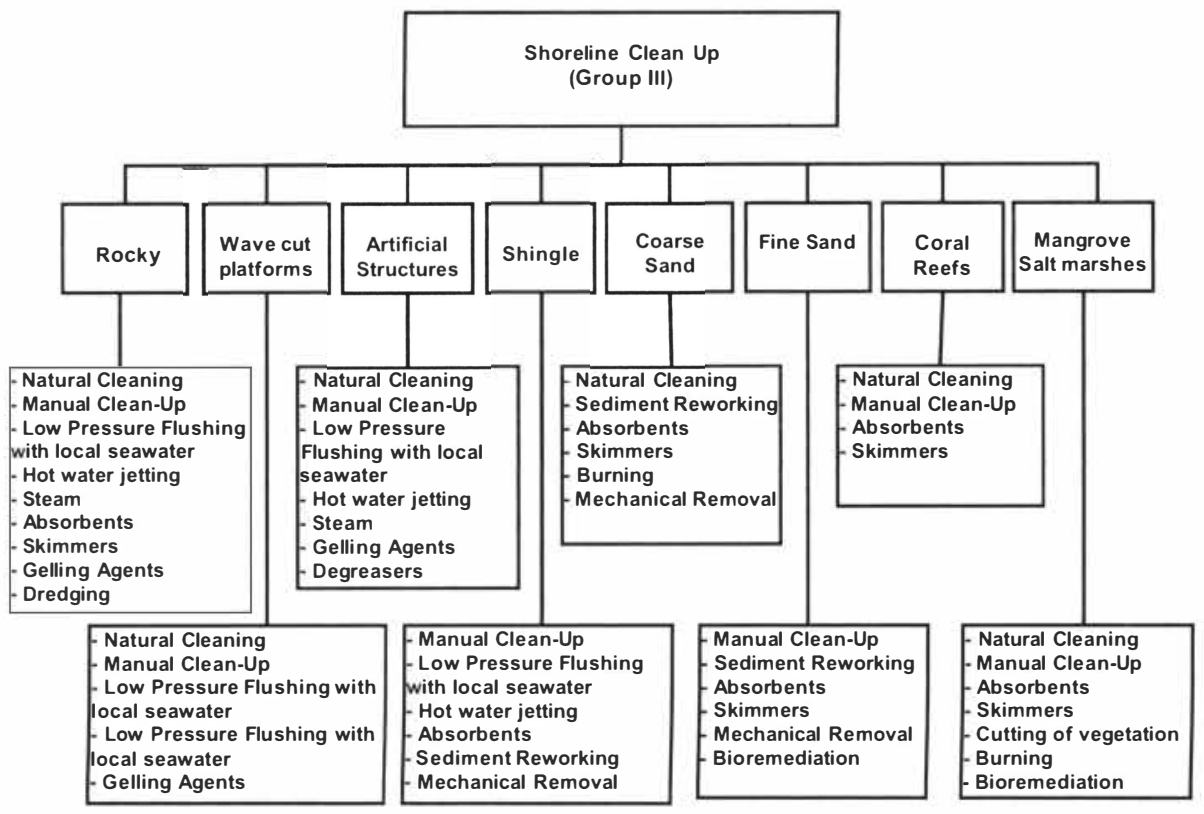

Figure 7. Decision tree for strategyeof shoreline cleanup of spill with oil Group III.

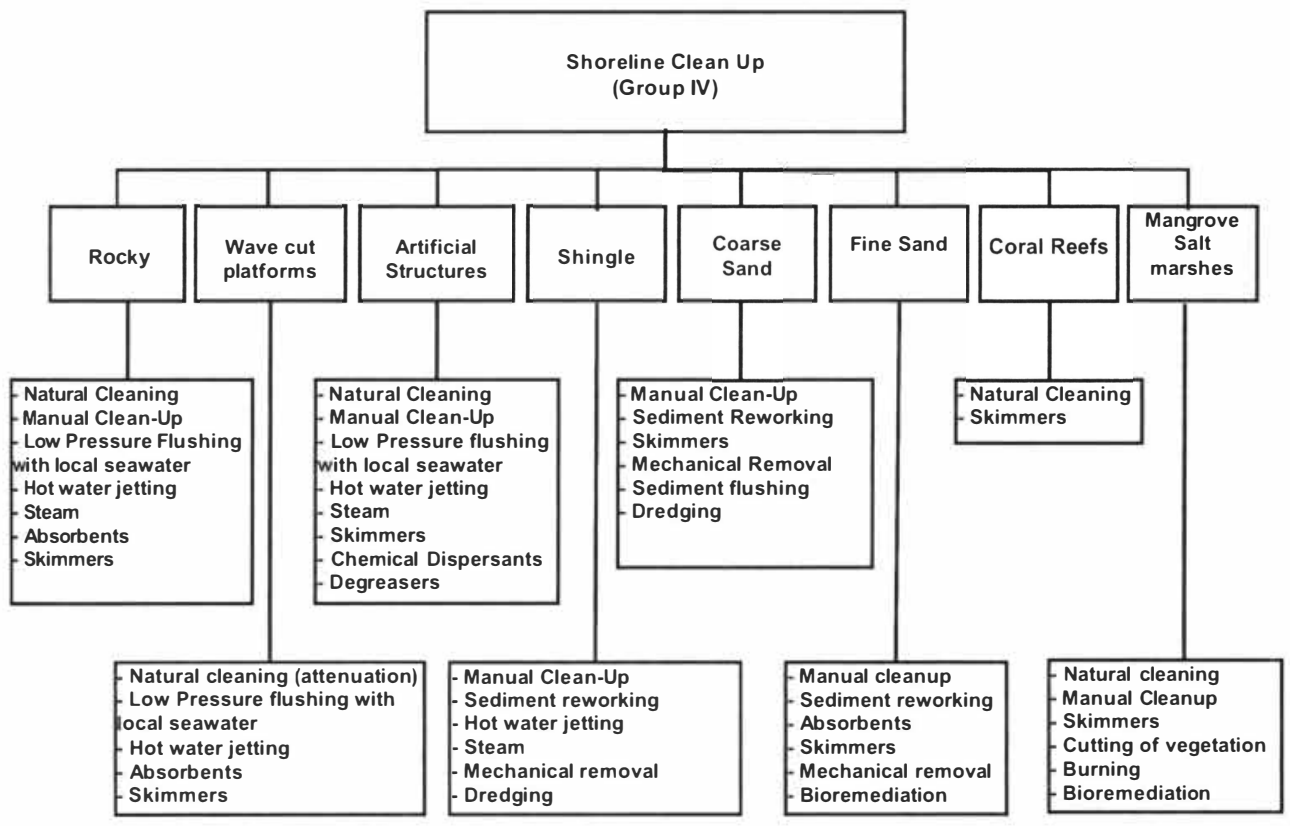

Figure 8. Decision tree for strategy of shoreline clean up - spill with oil Group IV. 


\subsection{Storage, treatment and disposal according to the oily waste composition}

Data from previous oil spill incidents on coastlines suggest that in some cases, the final volume of oily residue can be 30 times larger than the original oil volume spilled. There are many reasons that explain the large quantities of generated residues. It has been demonstrated that even small incidents can generate large amounts of residues, depending on the strategy for response. The coastal cleaning in particular generates large amounts of oily residues classified as hazardous waste that require proper handling. All organized harbor and platform installations, as well as support facilities should have obligatorily infrastructure to receive and treat several types of residues according to the criteria established by the environmental authorities [15]. The treatment/final disposal of these residues shall be given high priority [14]. The separation of hazardous from non-hazardous waste is a very important procedure and can be done in two ways: (i) preferable through separation at the source and separated storage or (ii) as second options, by segregation after collection. The type of storage used is another important aspect. The containers shall be constructed with inert material and shall adsorb as little oil as possible on their walls. Fig. 9 shows different waste handling depending on the classification of the oil that has been spilled.

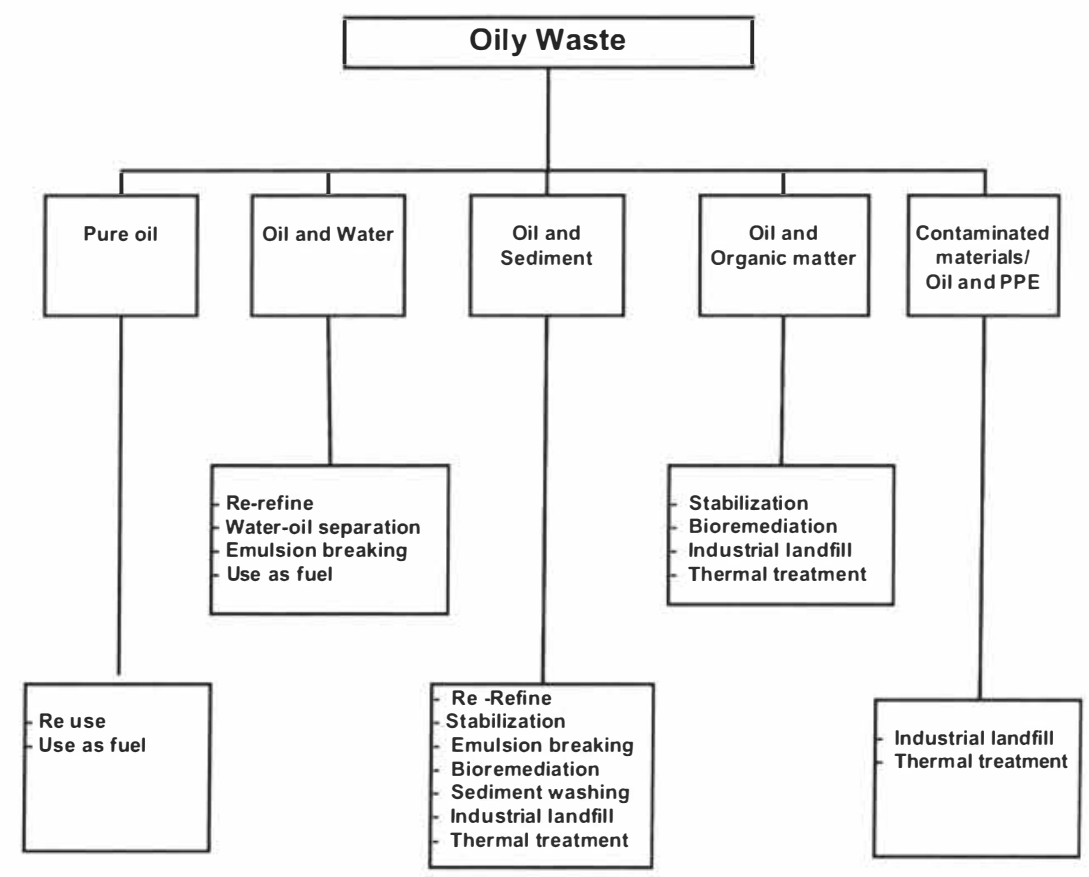

Figure 9. Oily waste recovery/treamentidisposal according to IPIECA (2004). 


\section{CONCLUSIONS}

Due to the enormous heterogeneity in composition of different crude oils and oil-based products and the morphological diversity of coastal ecosystems, the types and extension of potential impacts resulting from oil spills vary tremendously. As a consequence, there are many strategic responses that can be adopted as well as cleaning techniques options. Contingency plans, sensibility maps, software packages for modelling plume dispersion and decision trees are all tools to facilitate the choices to be made and speed up the decision process. The methodologies and techniques described in the decision trees here suggested can be adapted and modified according to the environment sensibility and legislation. Other decision trees also developed by the authors include choosing the best boom and skimmers. The establishment of requirements for logistics as well as aerial supervision and monitoring are topics to be further developed. Although the pressure is usually to prioritise economic and aesthetic values, the ecological aspects should come first when choosing the best strategy to respond to an oil spill incident

\section{ACKNOWLEDGEMENT}

This work was part of the MSc thesis in Environmental Engineering developed by the first author and supervised by the second at Rio de Janeiro State University-UERJ, Brazil. The second author acknowledges the financial support from The Brazilian National Council of Technological and Scientific Development-CNPq and the Swedish Foundation for International Cooperation in Research and Higher Education-STINT. The authors are also thankful to Mr Mark Francis, Consultant of Briggs Marine Environmental Services Ltd. for discussions and valuable contribution to the development of the decision trees.

\section{REFERENCES}

[1] NOAA, 2001. Selección de Alternativas para Responder a Derrames de Petróleo.

[2] NOAA, 1992. Summaries of significant U.S and International Spills.7-8.

[3] IPIECA, 2000. Elección de opciones de respuesta a derrames para minimizar los daños. Análisis del Beneficio Ambiental Neto. Vol 10.

[4] American Petroleum Institute, National Oceanic and Atmospheric Administration, U.S. Coast Guard, U.S. Environmental Protection Agency. Characteristics of Response Strategies: A Guide for Spill Response Planning in Marine Environments.

[5] Companhia de Tecnologia de Saneamento Ambiental - CETESB. 2002. Derrames de Óleo no Mar e os Ecossistemas Costeiros. São Paulo. Apostila de Curso.

[6] httpe//www.itopf.com/fate.html. Site accessed in September 2007.

[7] ITOPF, 2007. The International Tanker Owners Pollution Federation Limited. ITOPF Handbook 2007/2008. pl4.

[8] CONAMA 269, 2000. Ministério do Meio Ambiente Conselho Nacional do Meio Ambiente-CONAMA. Resolução $\mathrm{n}^{\mathrm{o}}$ 269, Regulamento para uso de dispersantes químicos em derrames de óleo no mar. p4-6.

[9] Cantagallo C., Milanelli J. \& Brito D., Limpeza de ambientes costeiros brasileiros contaminados por petróleo: Uma revisão. Pan American Journal of Aquatic Sciences.

[10] Michel, J., Shigenaka, G. \& Hoff, R. 1992. p. 1-103. Oil Spill Response and Clean up Techniques. In: An Introduction to Coastal Habitats and Biological Resources for Oil Spill Response. NOAA, Seattle, $401 \mathrm{p}$. 
[11] Hayes M., Hoff R., Michel J., Scholz D., Shigenaka G. 2004. An introduction to coastal habitats and biological resources for oil spill response. Hazardous Materials Response and Assessment Division National Oceanic and Atmospheric Administration. pp. 4.

[12] Kerabrun, L., Parker H., 1998. When should clean-up operations be brought to a closeHow Cleans is clean? Paper presented at 20 years after Amoco Cadiz Symposium, 1517 October 1998 Brest, France.

[13] ASTM 2004. Standard guide for describing shoreline response techniques. ASTM Designation: F 2204-02. Pg 1.

[14] IPIECA, 2004. Guidelines for oil spill waste minimization and management. Ipieca Report Series Vol 12. pp. 3-12.

[15] BRASIL. 2000. Lei 9966, Presidência da República, Sub-Chefia para Assuntos Jurídicos, 2000. Dispõe sobre a prevenção, o controle e a fiscalização da poluição causada por lançamento de óleo e outras substâncias nocivas ou perigosas em águas sob jurisdição nacional e dá outras providências. Published in D.O. 29 April 2000. 